\title{
Vorticity for the assessment of pulmonary vascular hemodynamics in pulmonary arterial hypertension
}

\author{
Alexander Honeyman ${ }^{*}$, James Browning ${ }^{2}$, Jean Hertzberg ${ }^{2}$, Joyce D Schroeder ${ }^{3}$, Aurelien F Stalder ${ }^{4}$, \\ J Kern Buckner ${ }^{1}$, Brett Fenster ${ }^{1}$
}

From 17th Annual SCMR Scientific Sessions

New Orleans, LA, USA. 16-19 January 2014

\section{Background}

4D flow CMR analysis of main pulmonary artery (MPA) flow in pulmonary arterial hypertension (PAH) has demonstrated vortical formations whose existence time correlates with mean pulmonary arterial pressure (MPAP). Vorticity can quantitate the rotation of these vortices and may represent a novel way to assess pulmonary arterial hemodynamics. We aimed to determine if MPA vorticity correlates with pulmonary vascular hemodynamics in PAH subjects when compared to controls using 4D flow CMR.

\section{Methods}

Seven PAH subjects ( 5 females/2 males) and 4 agematched controls ( 3 females/1 male) underwent same-day right heart catheterization (RHC) and 4D flow CMR. MPAP, pulmonary vascular resistance (PVR), pulmonary capillary wedge pressure (PCWP), and stroke volume (SV) were measured during RHC. Pulmonary vascular compliance $(\mathrm{Ca})$ was calculated by dividing SV by pulmonary pulse pressure. 4D flow CMR was performed with interleaved 3-directional velocity encoding (spatial resolution = $3.5 \times 2.6 \times 3.0 \mathrm{~mm} 3, \alpha=15^{\circ}, \mathrm{TE} / \mathrm{TR}=2.85 / 48.56 \mathrm{~ms}$, venc $=150 \mathrm{~cm} / \mathrm{s}$, temporal resolution $=50 \mathrm{~ms})$ on a $1.5 \mathrm{~T}$ MRI system (Avanto, Siemens, Germany) using ECG gating and respiratory navigation. Images were acquired in a sagittal oblique 3D volume covering the entire right heart and MPA. Datasets were corrected for noise (Jelena Bock, Northwestern University) and aliasing using a custom Matlab program. Corrected data was imported into Paraview (Kitware, Clifton, NY) for isolation of the MPA.

${ }^{1}$ Division of Cardiology, National Jewish Health, Denver, Colorado, USA Full list of author information is available at the end of the article
MPA peak systolic vorticity was then calculated using Paraview. Univariate regression analysis was used to test the relationship between peak systolic vorticity and pulmonary hemodynamics using JMP (SAS, Cary, NC).

\section{Results}

No significant difference in age, gender, or body mass index existed between the control and PAH groups. When PAH subjects were compared to controls, MPAP was significantly elevated ( $42 \pm 15 \mathrm{vs} .22 \pm 1 \mathrm{mmHg}, \mathrm{p} 0.02)$, compliance was significantly reduced $(1.4 \pm 0.8 \mathrm{cc} / \mathrm{mmHg}$ vs. $4.0 \pm 1.8 \mathrm{cc} / \mathrm{mmHg}, \mathrm{p}<0.01)$, and PVR was elevated $(11 \pm 9$ vs. $2 \pm 1$ Woods units, $\mathrm{p} 0.05)$. MPA vorticity was significantly reduced in PAH subjects $(3904 \pm 3254$ vs. $10070 \pm 75851 / \mathrm{s}$ ) and correlated with all indices of afterload including $\mathrm{Ca}$ ( $\mathrm{r} 0.92, \mathrm{p}<.001)$, MPAP ( $\mathrm{r} 0.63$, p 0.04), as well as PVR (r 0.62, p 0.04).

\section{Conclusions}

In a small cohort, MPA peak systolic vorticity was reduced in PAH subjects and correlated with all invasivelymeasured pulmonary vascular hemodynamics. 4D CMRderived MPA vorticity may represent a novel research tool to the study the role of complex blood flow formations in the pathogenesis and hemodynamic progression of $\mathrm{PAH}$.

\section{Funding}

Siemens Medical Solutions.

\section{Authors' details}

${ }^{1}$ Division of Cardiology, National Jewish Health, Denver, Colorado, USA. ${ }^{2}$ Mechanical Engineering, University of Colorado, Boulder, Colorado, USA. ${ }^{3}$ Division of Radiology, National Jewish Health, Denver, Colorado, USA.

${ }^{4}$ Magnetic Resonance, Imaging and Therapy, Healthcare Sector, Siemens AG, Erlangen, Germany. 
Published: 16 January 2014

doi:10.1186/1532-429X-16-S1-P15

Cite this article as: Honeyman et al: Vorticity for the assessment of pulmonary vascular hemodynamics in pulmonary arterial hypertension. Journal of Cardiovascular Magnetic Resonance 2014 16(Suppl 1):P15.

Submit your next manuscript to BioMed Central and take full advantage of:

- Convenient online submission

- Thorough peer review

- No space constraints or color figure charges

- Immediate publication on acceptance

- Inclusion in PubMed, CAS, Scopus and Google Scholar

- Research which is freely available for redistribution

Submit your manuscript at www.biomedcentral.com/submit
C Biomed Central 